\title{
ARTICLE
}

\section{Development of a PSF-detector for contaminated areas}

\author{
Hideho Gamo $^{\mathrm{a}^{*}}$, Masahiro Kondo ${ }^{\mathrm{a}}$, Tomoharu Hashimoto ${ }^{\mathrm{a}}$, Ryuichi Tayama ${ }^{\mathrm{a}}$ and Toshihisa Tsukiyama ${ }^{\mathrm{a}}$ \\ ${ }^{a}$ Hitachi-GE Nuclear Energy, Ltd., 3-1-1, Saiwai-cho, Hitachi-shi, 317-0073, Japan
}

\begin{abstract}
Hitachi-GE Nuclear Energy, Ltd. has developed the Dose rate meter called "D-phod (Detector for photon dose)" using fiber optics as a radiation sensor to figure out the dose rate of Fukushima area which is contaminated by radioactive materials. D-phod is a tool that can rapidly measure linear or curved dose rate up to $20 \mathrm{~m}$ along fiber optics. Element technology has already established, however, existing measurement system is unfit to measure environmental dose rate. Therefore, we improved it to be able to be used as a survey meter and completed D-phod. It enables to measure a wide range of environment reasonably. In this paper, we report the development of D-phod which solved the problems mentioned above and can be put into practical use.
\end{abstract}

Keywords: D-Phod; dose rate; detector; plastic scintillation fiber; PSF; time of flight technique; TOF

\section{Introduction}

Photon dose rates must be measured efficiently in a huge and wide contaminated area for conducting decontamination tasks in Fukushima. It requires for decontamination tasks to figure out the state of contamination and to measure the effectiveness of decontamination. Survey meters are used under present conditions, although quick and accurate measurements are requested. Moreover, the survey meters are not available for measurements in rivers, ponds, and on trees, roofs and the outer surface of buildings - places that are not easily accessible by humans.

To resolve those problems, we focused on a dose monitor system by using plastic scintillation fiber (PSF) and the time of flight technique (TOF). As radiation measurement by PSF enables to conduct distribution measurement along fiber optics at once, it is expected to measure radiation reasonably in contaminated areas. In addition, even though PSF is put under water, underwater measurement is possible. However, existing PSF measurement equipments have following problems and cannot be applied for environment measurement as they are. The problems are: a.) They are large, heavy and not portable, b.) Wiring is complicated, c.) Measurement sensitivity is low, d.) They cannot be used outside since they are not waterproof or dustproof, e.) High costs, etc.

We report the development of D-phod specialized for environment measurement below.

\section{Measurement principle}

PSF measurement is the technology that was jointly

*Corresponding author. Email: hideho.gamo.xo@hitachi.com developed by Tokyo university and Power Reactor and Nuclear Fuel Development Corporation about 20 years ago [1]. Concept of the measurement principle is shown in Figure 1. The part of PSF is a radiation sensor. When gamma rays reach PSF, scintillation pulses which are about three nano-seconds in time width are generated. Light pulses are transmitted to the both sides inside PSF, and these are converted into electric pulse signals by PMT connected to the both sides of PSF. Electrical pulses are shaped through CFD, time lag measured at the both sides of PSF is determined at TAC. From this time lag, the location where PSF emits light by gamma rays, which is radiation source, can be obtained. The center location of PSF is to be where there is no time lag. Since TAC only can measure positive value of time lag, one of the signals are forcibly delayed at the Delay circuit not to calculate minus value of time lag.

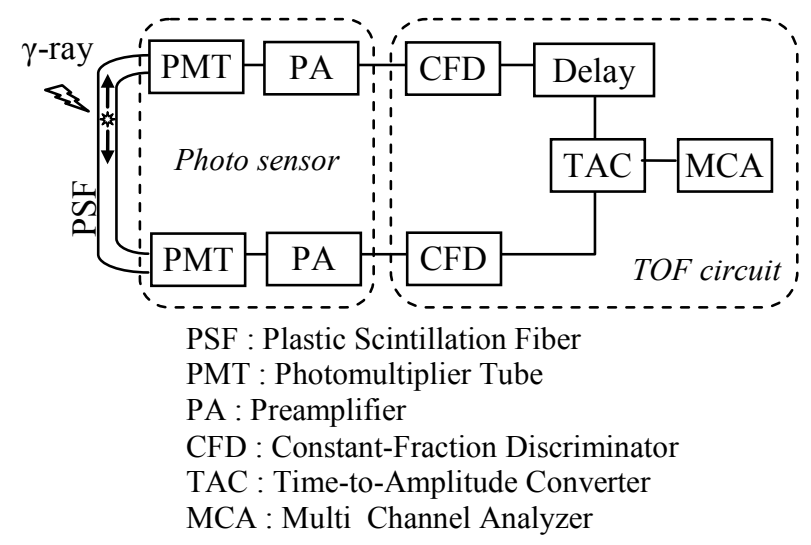

Figure 1. PSF measurement system using TOF 


\section{Development of D-phod}

Figure 2 shows the appearance of D-phod, which Hitachi-GE Nuclear Energy, Ltd. has developed and Table 1 shows its main specification. In this chapter, it describes characteristic of PSF part, simplification and outdoor usage.

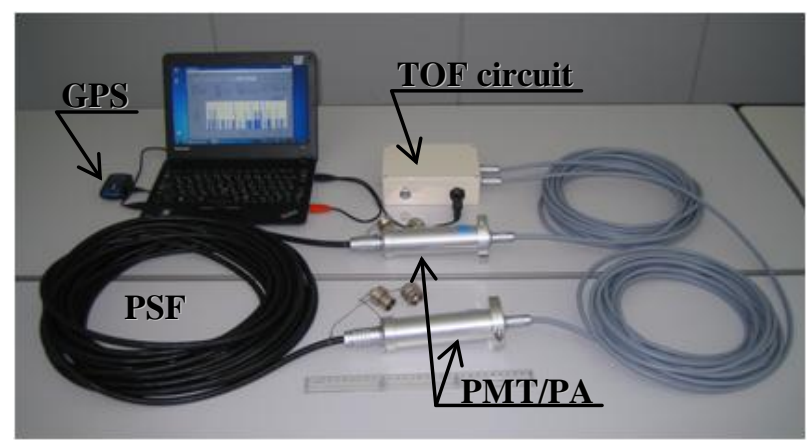

Figure 2. Appearance of D-phod

Table 1. Specification of D-phod

\begin{tabular}{|c|c|c|}
\hline $\begin{array}{l}\text { Radiation } \\
\text { detected }\end{array}$ & Gamma-ray & Notes \\
\hline Detector & PSF & \\
\hline $\begin{array}{l}\text { Measurement } \\
\text { range }\end{array}$ & $\begin{array}{l}0.1 \sim 120 \mu \mathrm{Sv} / \mathrm{h} \text { (Low sensitivity) } \\
0.1 \sim 20 \mu \mathrm{Sv} / \mathrm{h} \text { (Normal) } \\
0.1 \sim 8 \mu \mathrm{Sv} / \mathrm{h} \text { (High sensitivity) }\end{array}$ & $* 1$ \\
\hline $\begin{array}{l}\text { Measurement } \\
\text { time }\end{array}$ & $\begin{array}{l}\text { several seconds } \\
\text { (Average along the PSF) } \\
\text { several minutes } \\
\text { (Distribution along the PSF) }\end{array}$ & $* 2$ \\
\hline PSF Length & Max. 20m & \\
\hline $\begin{array}{l}\text { Power } \\
\text { supply }\end{array}$ & PC USB & $* 3$ \\
\hline FWHM & $1 \mathrm{~m}$ & \\
\hline Mass & $\begin{array}{l}2.5 \mathrm{~kg} \text { (Low sensitivity) } \\
5 \mathrm{~kg} \text { (Normal) } \\
8 \mathrm{~kg} \text { (High sensitivity) } \\
0.5 \mathrm{~kg} \text { (TOF circuit) }\end{array}$ & $\begin{array}{l}20 \mathrm{~m} \\
20 \mathrm{~m} \\
20 \mathrm{~m}\end{array}$ \\
\hline $\begin{array}{l}\text { GPS } \\
\text { Accuracy }\end{array}$ & $5 \mathrm{~m}$ & \\
\hline
\end{tabular}

*1: Average dose rate along the PSF. In the case that PSF length is $10 \mathrm{~m}$.

*2: At $0.1 \mu \mathrm{Sv} / \mathrm{h}$, high sensitivity, measurement error \pm $10 \%(1 \sigma)$.

*3: Secondary batteries (optional)

\subsection{PSF part}

PSF part which detects radiation contacts a measurement target directly and is also long. It needs to be assumed that PSF part is handled roughly when a measurer moves PSF or rewinds PSF to store. Therefore, PSF is designed to consider the toughness in bend and stamp as inserted into a metallic flexible tube. In addition, both sides of PSF can be easily insert into or pull out PMT by connectors.

The sensitivity of PSF to radiation can be chosen from 3 levels, low, normal and high, depending on the radiation level of the measurement target and required measurement time. These are the bundles of $1 \mathrm{PSF}, 7$ PSF and 12 PSF. If number of bundles is increased, it gets thicker and portability decreases, however, measurement time gets short due to high sensitivity. For instance, in case of low sensitivity type and measurement target is $0.1 \mu \mathrm{Sv} / \mathrm{h}$, it is need several ten seconds in measurement error $\pm 10 \%(1 \sigma)$. Sensitivity of high sensitivity type is about 10 times higher than low type and measurement time gets to be several seconds. Therefore, high sensitivity type is more efficient when measurement is conducted in a wide area where dose rate is comparatively low. It needs to be careful that dose rate level of measurement limit for high sensitivity type gets lower.

\subsection{Simplification}

Figure 3 shows existing device which needs about a dozen of signal cables and low-voltage power cable to connect TOF circuits composed of PMT, PA and Nuclear Instrument Modules(NIM).

Significant simplification is performed on D-phod. Cables required for D-phod are 2 PMT output cables and 1 USB cable of PC. There is no control knob. This simplification makes anyone can use PSF measurement system which only experts of measurement had been able to use. Simplification on PMT part and TOF circuit part is described below.

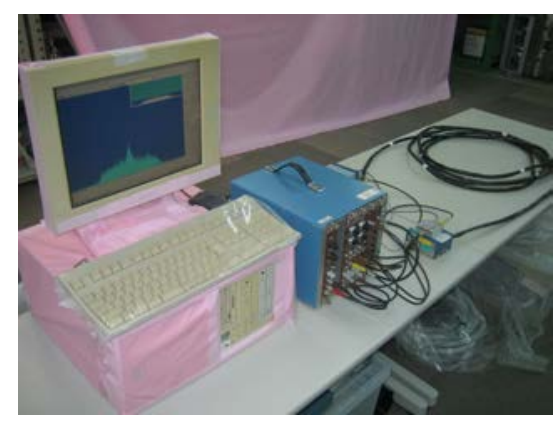

Figure 3. Existing device

\subsubsection{PMT part}

Scintillation pulse generated PSF is converted to electrical signal at PMT and the electrical signal is amplified at PA. PMT and PA are unified to improve the portability. Composite cable which composites electrical signal output of PA and low-voltage power supply input is adopted to reduce number of cables.

\subsubsection{TOF circuit}

Existing TOF circuit, the heart of PSF measurement device, is consisted of combined NIM instruments. Wight of the circuit part is about $20 \mathrm{~kg}$. $100 \mathrm{~V}$ AC power source is needed to use. If it is used outdoors, dynamo is necessary. Therefore, there is less portability to use it for environment measurement in Fukushima.

Key point of reduction in size and weight of whole system is to improve TOF circuit part. Therefore, 
functions and performances have been selected. For instance, for TAC part, existing device can correspond to various length of PSF since measurement range is variable. On D-phod, TAC range is set as the length of PSF is up to $20 \mathrm{~m}$. For MCA part, it is common that maximum count rate is Mcps under the current technology. On D-phod, it is held down to about $10 \mathrm{kcps}$ for power saving. Due to these selections, it has been succeeded to reduce the weight of TOF circuit part from $20 \mathrm{~kg}$ to $0.5 \mathrm{~kg}$. The reason why measurement rage gets low with PSF of the said high sensitivity type is to hold down the count rate of MCA. If ultrafast MCA was selected here, it would be possible to cover wide measurement rage with only one kind of PSF, however, power saving and low-cost were prioritized.

\subsection{Outdoor specifications}

Since D-phod is used outside, it is needed to consider waterproof and dustproof. As there is a need to measure rivers and ponds, the bundle of PSF part is IP 68 (10 meters below the water surface). Light connectors and light detection part are IP66 to resist rain and spray from high-pressure water jetting used for decontamination. TOF circuit part is designed by IP54. IP standard is established in accordance with JIS and IEC standards and describes protection code of electric devices. To take same examples, IP68 means it is possible to be submerged, IP66 means it is possible to be used in rainy weather and IP54 means dust protected.

Not only dose rate data obtained from measurement but also where the data is obtained is important. D-phod equips Global Positioning System (GPS) as standard and records measurement location information as well as dose rate data.

D-phod has been developed under the design concept described above. Comparing existing PSF system, it archived to downsize and simplify significantly and to design for outdoor usage.

\section{D-phod application result}

We used D-phod and measured in actual contaminated environment. Figure 4 shows the measurement along with the road. 3 hot spots were clearly measured. As it matched well with the measured value by NaI survey meter (TCS-161 of Hitachi Aloka Medical, Ltd.), it can be said that measurement accuracy of D-phod is equal to one of $\mathrm{NaI}$ survey meter.

On environment measurement, there is a need for measurement in various places. D-phod can be used as it is on the ground of comparatively small areas such as yards. Usability can be improved (high efficient measurement) to attach something pole to D-phod for high places, and for large areas such as roads, D-phod can be attached on a car. Measurement under water is also possible if PSF part is submerged. Following pictures (Figure 5-8) show measurement in a vertical direction such as walls, trees, etc., measurement of a

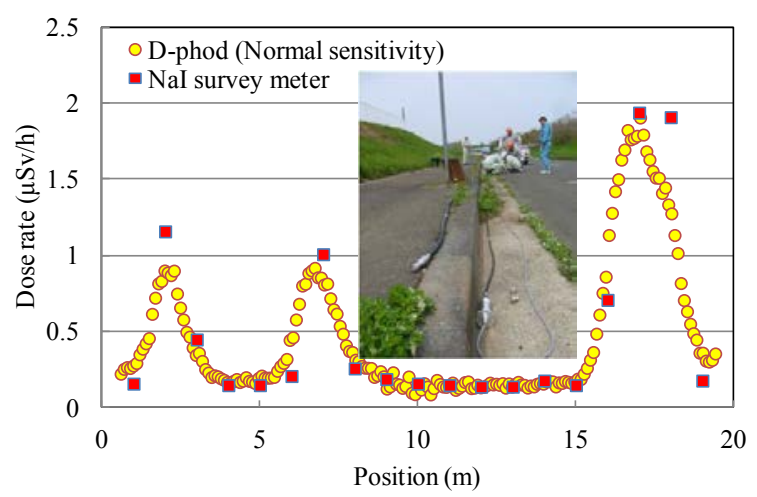

Figure 4. Measurement result along with the road

road with attaching D-phod on a car and measurement under water, which are difficult to measure for existing survey meters.

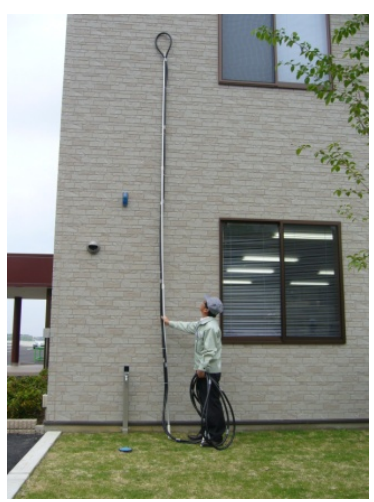

Figure 5. Wall

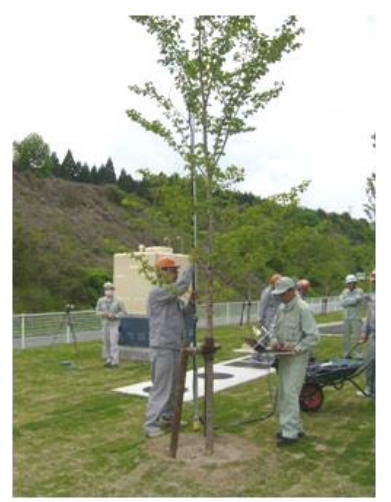

Figure 6. Tree

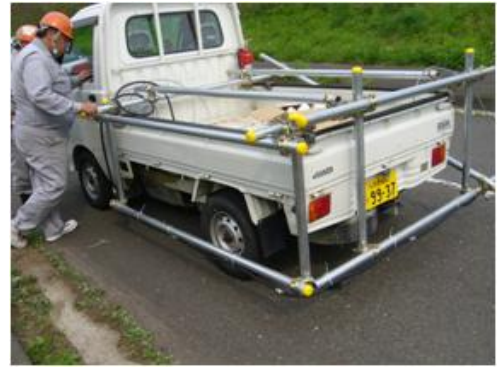

Figure 7. Attaching on a car

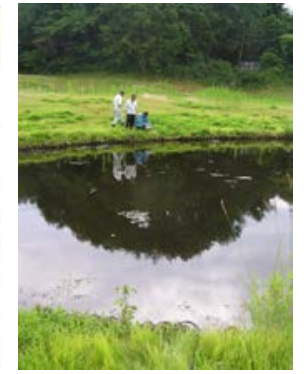

Figure 8. Under water

\section{Software development status}

Hitachi group has developed software which enables dose rate data obtained by D-phod to be easily recorded and stored and to be visually shown for easy understanding.

\subsection{SOPHIDA}

SOPHIDA which Hitachi-GE Nuclear Energy, Ltd. has developed displays areas of radiation source and source intensity as a map [2]. Combining D-phod with 
SOPHIDA, it is possible to be shown as a dose rate map instantly, from vast amounts of measured data and location information. On decontamination work, it enables efficiently to plan on dose rate measurement and decontamination work and to evaluate expected effect.

SOPHIDA is effective software for visualization of comparatively large areas such as a village, town and city since its mesh unit is $10 \mathrm{~m}$. Figure 9 shows a example of radiation dose rate evaluation results using SOPHIDA

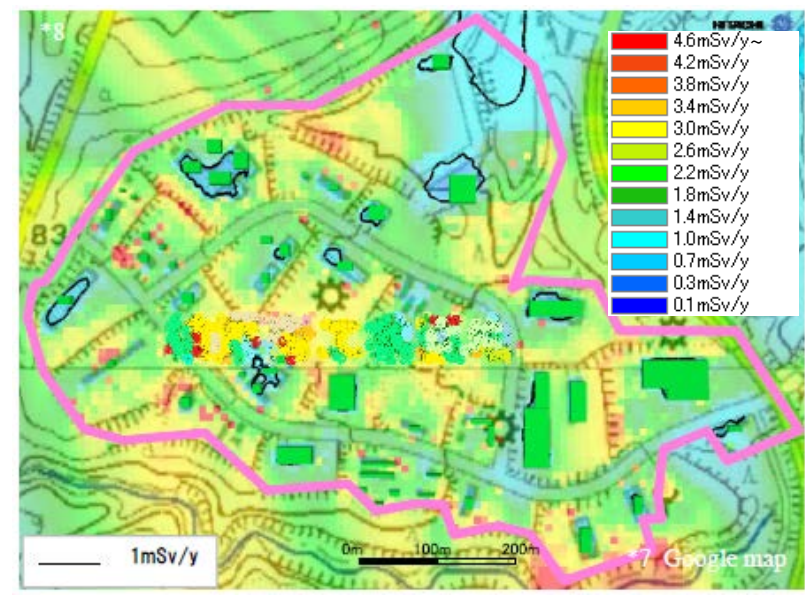

Figure 9. Example of radiation dose rate evaluation results using SOPHIDA

\subsection{D-phod Viewer}

SOPHIDA is comparatively effective to visualize macro areas. Software which controls detailed information in comparatively small areas is D-phod Viewer. Its mesh unit is $1 \mathrm{~m}$.

It supports each electronic map of aerial photographs, residence maps, etc. and enables to make measurement plan easily. Measurement result can be plotted on a map in color. It manages several measurement data of D-phod and pictures taken at measuring. For instance, if it is shown by each measurement time, such as time before and after decontamination, it is effective to confirm the result of decontamination. Furthermore, there is a function to attach the measurement result of D-phod in color to pictures taken at measuring. These functions enable to make a report of measurement result which is easy to understand visually. Figure 10 shows a sample of a report produced by D- phod Viewer.

To use "D-phod Viewer", it makes possible effectively to conduct the whole measurement work from planning measurement through making a report.

\section{Conclusion}

D-phod which achieved reduction in size and weight and outdoor use of existing PSF system has been

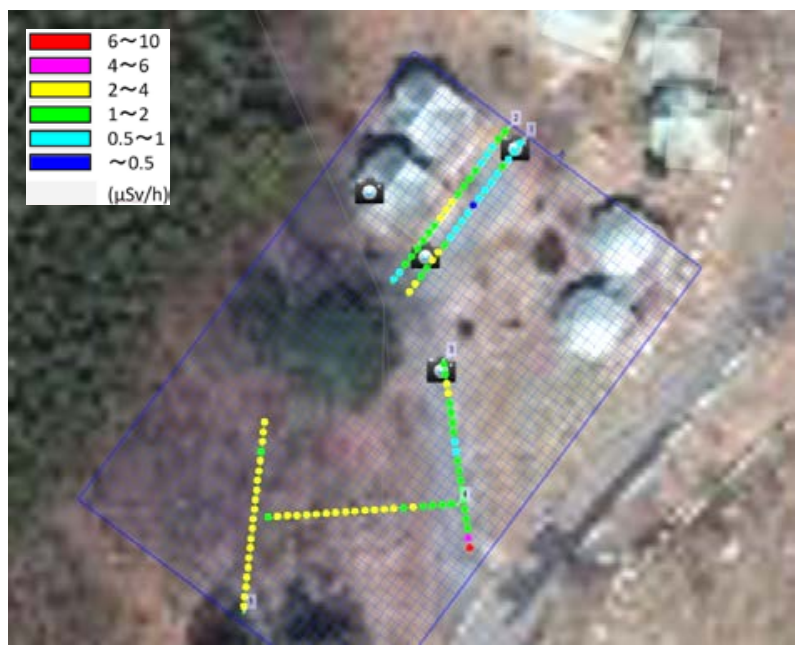

Figure 10. Sample of measurement report using D-phod Viewer

developed effectively to measure the status of environmental contamination and the effect of decontamination associated with Fukushima Daiichi NPP accident. As the result of a field test using D-phod, it was confirmed that it was possible to measure $0.23 \mu \mathrm{Sv} / \mathrm{h}$ which is the threshold value for decontamination in a few seconds and useful to measure rationally high places with special tool. SOPHIDA and D-phod Viewer show power in explanation to inhabitants.

Under the original government policy that decontamination would be completed in 2013, D-phod was started productization with hoping residents who are evacuated to each place can go back to their hometown at an early stage. However, there are problems on a temporary place to store and temporary storage facility, so decontamination has not been unfortunately proceeded as the original plan. Taking an example of this situation, it can be compared to the situation that a sophisticated car has been developed but a road has not completed yet. Our development team desperately hope that each problem will be solved as early as possible, residents who are evacuated will be back home and disaster-hit areas will be recovered.

\section{References}

[1] T. Emoto, T. Torii, T. Nozaki and H. Ando, Measurement of spatial dose-rate distribution using a position sensitive detector, Proceedings of the 8th Workshop on Radiation Detectors and Their Uses, KEK, Tsukuba, Japan, Jan 25 - 27, 1994, KEK Proceedings 94-7 (1994) 119-125.

[2] Hitachi-GE Nuclear Energy Starts Outsourcing Business for the Source of Photons and Integrated Does Analysis http://www.hitachi-hgne.co.jp/en/news/2011/20111 222.html 